\title{
"It's More than Doing Sports Together, You Know. It's Deeply Personal": Preliminary Findings of an Ongoing Qualitative Study on the Relationships between Personal Fitness Trainers and Trainees
}

\author{
Ceren Doğan \\ Psychology Department, Yaşar University, Izmir, Turkey \\ Email: ceren_dogan@gmx.de
}

How to cite this paper: Doğan, C. (2017)

"It's More than Doing Sports Together, You Know. It's Deeply Personal”: Preliminary Findings of an Ongoing Qualitative Study on the Relationships between Personal Fitness Trainers and Trainees. Open Journal of Social Sciences, 5, 106-114. https://doi.org/10.4236/jss.2017.59008

Received: August 15, 2017

Accepted: September 10, 2017

Published: September 13, 2017

Copyright $\odot 2017$ by author and Scientific Research Publishing Inc. This work is licensed under the Creative Commons Attribution International License (CC BY 4.0).

http://creativecommons.org/licenses/by/4.0/

\begin{abstract}
Training at the gym has become, without question, one of the most popular leisure pursuits in contemporary Western societies. In addition to conventional forms of fitness training with free weights, on machines or in exercise-to-music classes, more and more gym members decide to work out with a certified personal trainer on a one-to-one basis, often over long periods of time. The purpose of this ongoing study is to explore the relationship between personal fitness trainers and trainees with a focus on their subjective experiences. Eight semi-structured, in-depth interviews were conducted so far and analysed through a thematic analysis. Two central themes have emerged from the data: First, the trainer-trainee relationship is for both sides more than a transactional event but an emotionally significant encounter. Second, trainees describe an occasional reversal of roles where they show interest in and concern about the trainer. Future research should account for possible gender differences, changes of relational dynamics over time and possible negative experiences of both trainers and trainees.
\end{abstract}

\section{Keywords}

Fitness, Gym, Personal Training, Interactive Service Work

\section{Introduction}

Training at the gym has become without question one of the most popular leisure pursuits in contemporary Western societies [1]-[7]. Fitness gyms vary in location, membership fees and serve different social and economic milieus. Whilst 
strength training on machines and exercise-to-music group work-outs remain at the heart of most gyms, more and more members decide to work with a personal trainer, often several times a week and in addition to their usual training [8] [9]. Personal fitness trainers are certified professionals who work with clients on a one-to-one basis. They design individualised exercise programs for their clients, monitor and measure their progress, provide feedback, and they educate their clients in physical fitness, health and nutrition. Their most important role, however, is to motivate their trainees in achieving certain fitness goals. The purpose of this study is to explore the relationship between clients and personal trainers in more depth. The focus is on the lived experiences of participants as they interact and relate to each other. By shedding light onto one of the most popular leisure activities in Western societies, this study seeks to make a contribution to the sociology of everyday life.

In the social science literature, personal training is being discussed from different angles. The increase of gyms and certified training professionals over the past decades has led to growing competition on the market and as a consequence to a decrease of personal training fees. Hence it became affordable to many and could be purchased especially by those who aspired to the way of life associated with glamour and affluence [10]. Hence, it is argued that going to the gym and hiring a personal trainer are not only indicators of economic capital but also of "cultural capital" [11], that is, certain behaviours and skills that allude to one's cultural competences [12] [13] [14].

Another strand in the literature argues from a Foucauldian view that gym training in general, and personal training in particular can be regarded as examples of so-called "self-entrepreneurial practices" [15] [16]. The prompt on the enterprising self is to make a good impression by looking healthy and energetic and by showing willingness to succeed in life. The ethos of the enterprising self is ultimate commitment, motivation and a can-do attitude towards all areas of life. Most importantly, it carries the impetus to work upon the self [17] [18]. It is argued that in neoliberal societies "becoming" and "inventing one's self" are understood as desirable practices, and that the gym invites individuals to work towards better versions of themselves. This is, as some authors state [19] [20] also in line with neoliberal, post-welfare conceptualizations of health that seek to increase the number of active, self-reliant and self-responsible citizens.

Andreasson and Johansson (2014) provide a different perspective on personal training suggesting that personalised one-to-one exercise provides an alternative to what has been described as the McDonaldization of gym training [1]. McDonaldization, a term coined by Ritzer (2008), describes how contemporary social practices are permeated by principles of efficiency, calculability, predictability, standardization, and control [21]. In terms of the gym one may argue that conventional training on machines indeed consists of routines, repetitions and calculation of sets, circuits, weights and so on, which might yield boredom and lack of motivation. Personal trainers instruct, monitor and motivate their clients during a one-to-one encounter from which others are excluded which provides a funda- 
mentally different setting.

From the trainers' perspective, it has been noted that personal trainers must, like all interactive service workers, produce "emotional labour": they are expected to present themselves as warm, cheerful and attentive with the aim of selling their products [22]. As interactive service work entails the co-presence and co-participation of clients, employees must not only regulate their own feelings but also the feelings of their clients to an extent where formal certifications and technical know-how may even become secondary to social and emotional skills [23] [24]. Trainers have to establish good relationships with their trainees as they depend on long-term, loyal clients to guarantee their livelihood. This, in turn may impair their own well-being, leading to emotional exhaustion and even depression.

None of the literature cited above takes issue with the lived experiences of clients and personal trainers as they relate to each other. Indeed, there are only four empirical studies to my knowledge that look at personal training in more depth [25] [26] [27] [28]. Only George's (2008) study looks at participants' subjective experiences with an emphasis of how trainers negotiate the challenges of their jobs [28]. The focus of the present study is different: its aim is to explore the relational dynamics between clients and personal trainers by investigating the meanings they attach to their mutual relationship.

\section{Methodology}

The findings presented in this paper are preliminary as the study is still in process; they are based on 8 interviews in total; 6 interviews were conducted with fitness participants of which 5 were females and 1 male (abbreviated below as F1-F5 for the females and M1 for the male), and 2 interviews were conducted with personal trainers, both females (abbreviated below as T1 and T2). In the course of this study more interviews will be conducted and analysed. Interviews lasted between 30 minutes and one hour (see appendix for interview schedule). The age range of interviewees was between 25 and 64 years. All participants were located in London, United Kingdom. They were recruited through a combination of personal contacts and referrals. Semi-structured interviews with open-ended questions were employed (e.g. Do you and your trainer/client have particular training routines? How would you describe the relationship with your trainer/clients?). The interviews were analysed through a thematic analysis [29]. Two central themes have emerged from the data: First, the trainer-trainee relationship is for both sides more than a transactional event but an emotionally significant encounter. Second, there is occasional reversal of roles where the trainees show interest in and concern about the trainer.

\section{Preliminary Findings}

\section{1. "It's a Very Intimate Relationship": The Emotional Significance of the Trainer-Trainee Relationship}

The interviews indicate that for trainees a personal trainer is more than a neutral, 
exchangeable service provider. With the exception of one participant in this study, all participants have stated that the longer they worked out with a personal trainer, the emotionally significant their relationship became and the more reluctant they were to exercise with someone else. One interviewee who has been training with the same personal trainer for 2.5 years said that it has always been "about her rather than having just a personal trainer". Another interviewee told that her personal trainer was planning to go abroad for a year and rather than looking for another trainer she wanted to "wait for her to come back". In a similar vein, other interviewees stated:

F3: "I just like her. We chat a lot you know. I spend two hours a week with her and I like every minute of it. I said once to somebody, other than my partner who I live with, it is the second significant relationship in my life. And it's a joke but actually in terms of contact, yes, I spend more time with her than anybody else apart from my partner."

M1: "When you spend all this time together, sure, you get to know each other. I wouldn't say we are friends in a conventional sense, we don't go to the pub together, but there is definitely a sort of connection I don't have with many."

F2: "My last personal trainer was a young, handsome man in my sons' age and he was extremely supportive and attentive. I really enjoyed the time spend with him. I thought this is so much nicer than when my sons are with me (laughing)."

These accounts indicate that trainees do not regard themselves just as "clients" and their trainers as "fitness experts" but as two people in a genuinly personal encounter. From the accounts above one can infer that the more time both spend with each other the less "transactional" and the more interpersonal their interactions become, exceeding the limits of giving and receiving fitness instructions only. There might also be another and less obvious aspect accounting for the attachment to the trainer: Fitness participants typically hire a personal trainer because they want to transform their bodies in ways that the trainer with his or her own physicality has already achieved; in other words, he or she personifies the trainee's ideal self. It is very likely that a process of identification takes place, where the trainer's body shape, eating habits, motivational and can-do attitude ultimately become part of the trainee's own aspirations and commitments, which in turn, reinforces the attachement to this one trainer. If and to what extent this identification actually takes place needs to be clarified in the due course of the study.

Interviews with personal trainers indicate that they too relate in an interpersonal way to their clients. None of the trainers mentioned profitability as a motive which indicates that they do not form good relationships primarily for economic reasons. As the trainers put it:

T1: It's a very intimate relationship. I do socialize with my clients as well. We go out in the evenings. There is one client and I went to dinner with him and his wife many times. One client is an art lover. We debate about different works of art. It's more than sports together, you know. It's deeply personal. Maybe I am 
an atypical trainer. My second client today brought me a book that I should read, he said. It's a book about love and relationships. Actually you made me remember how much I like my work, how much I like working with clients.

T2: They are all friends, with only a few exceptions and that's not just me that's what all trainer friends do. It is a very private, intimate setting.

That the trainers of this study did not regard the emotional labour they accomplish as damaging or restricting but as rewarding is in line with George's (2008) findings [28]. However, it is important to bear in mind that according to the author's results there is a distinction between female and male trainers, suggesting that the latter are less emotionally involved in their interactions with clients and therefore less prone to emotional exhaustion. Given the limited number of trainers included in this study no comparisons could be made so that further research must shed light on potential gender differences.

\section{2. "I Keep an Eye on Her": Concern for the Other and Reversal of Roles}

Whilst personal trainers are expected to be sensitive to their clients' needs and concerns, the interviews in this study indicate that there is occasionally a reversal of roles where the clients start to take interest in the physical and emotional well-being of their trainers. Based on my interviews, I could identify two main areas of on-going curiosity and interest in the life of the trainer: the first has to do with the precarious job situation trainers may face on the market and the second with their physical and emotional well-being. Three participants have explicitly drew attention to the insecure employment situation of their trainers:

F5: I wonder what she is going to do once she has a baby. She says she wants to go back to work straight away but I don't think it's going to be that easy, just physically you know. I kind of understand why she wants to go back, she doesn't have a permanent contract and I don't think they'll give her maternity leave.

F6: We always run over time. Always. And she said to me she never books in someone else immediately after me because we always run over time. And I feel really really bad. (Interviewer: “Why do you feel bad?”) It's her livelihood! And I do think it is very very easy to just suck somebody's time because it's not an equal relationship. I'm paying her to make me feel better. I know that and she is completely brilliant at her job. And she has the right for that to stop after an hour.

F5: My trainer is a freelancer and it must be hard to work as a personal trainer, especially as a woman where you have to prove your credibility, your physical strength and abilities. I feel empathy for her in a way.

This sort of sensibility towards their trainers' employment conditions indicates that clients are not "blind" to what McDowell (2011) calls the "less successful and less glamorous side of service work", that is, the fact that service workers are usually not particularly well-paid, or provided with a secure and stable income [30]. Another area of concern participants brought up was related to their trainers' 
health. As two interviewees stated:

F2: My trainer smokes, she never told me but I know she does. And for her sake, I really mind. I've bitten my tongue about it loads of time, and also what would I say to her but I really wished she didn't because fitness is what she does for living and it's like, you need your lungs. But I bite my tongue about it.

F4: My personal trainer's body has changed a lot since we've been training. She has got a body that everyone would aspire to... When we started training together she was very thin and very strong but not particularly skinny. And recently she has been training very very hard, to the point where I start worrying about her at some point. We obviously talk about food because that's part of the training and she always asks me what I had for breakfast, she always makes sure that I eat something for breakfast. Once I asked her what she was having for breakfast. I would never say, I think you are too thin but I try to keep an eye on her.

What seems to take place here is a temporary reversal of roles where the client worries about her trainer's health and well-being instead the other way around. Given the significance that trainees give to their relationship, this is perhaps not surprising. What is surprising though is the fact that clients do not directly communicate their concern to their trainers, possibly because they believe by doing so they would cross a professional boundary or question their trainers' authority. This indicates that the relationship is marked by what Van Luevan calls (2002) the negotiation of relational boundaries [27]. Under which circumstances these negotiations and role shifts take place remains to be explored.

\section{Conclusion, Limitations and Future Research Directions}

In sum, the two central themes have emerged from the data shedding light on the relationship between trainers and trainees, namely the emotional significance of the trainer-trainee relationship and the temporary reversal of roles, which indicate that personal fitness training is personal in more than one sense. Mutual interest in and concern for the other, also from a gender perspective, are aspects of this relationship worthy of more exploration. The limited number of research participants in this study did not allow for gender or age related comparisons; therefore the sample size needs to be increased. Another limitation of the present study stems from the fact that interviews were conducted only once. The question whether there are changes and fluctuations within this relationship over time, for example, remains to be addressed. Finally, the preliminary data analysis outlined in this paper draws attention to what has not been mentioned by participants, but nonetheless is noteworthy exploring in future, namely negative and unpleasant experiences of the trainer-trainee relationship.

\section{References}

[1] Andreasson, J. and Johansson, T. (2014) The Fitness Revolution. Historical Transformations in the Global Gym and Fitness Culture. Sport Science Review, 23, 
91-111. https://doi.org/10.2478/ssr-2014-0006

[2] Featherstone, M. (2010) Body, Image and Affect in Consumer Culture. Body \& Society, 16, 193-221. https://doi.org/10.1177/1357034X09354357

[3] Howson, A. (2013) The Body in Society: An Introduction. Polity Press, Cambridge, 150.

[4] Luciano, L. (2001) Looking Good: Male Body Image in Modern America. Hill and Wang, New York.

[5] Phillips, B. (2005) Working Out: Consumers and the Culture of Exercise. The Journal of Popular Culture, 38, 525-550. https://doi.org/10.1111/j.0022-3840.2005.00127.x

[6] Shilling, C. (2012) The Body and Social Theory. Sage, London. https://doi.org/10.4135/9781473914810

[7] Stebbins, R. (2009) Leisure and Consumption: Common Ground/Separate Worlds. Palgrave Macmillan, Basingstoke, 78. https://doi.org/10.1057/9780230244863

[8] Frew, M. and McGillivray, D. (2005) Health Clubs and Body Politic: Aesthetics and Quest for Physical Capital. Leisure Studies, 24, 161-175. https://doi.org/10.1080/0261436042000300432

[9] Smith Maguire, J.S. (2008) Fit for Consumption: Sociology and the Business of Fitness. Routledge, London and New York.

[10] Smith Maguire, J.S. (2008) Leisure and the Obligation of Self-Work: An Examination of the Fitness Field. Leisure Studies, 27, 59-75. https://doi.org/10.1080/02614360701605729

[11] Bourdieu, P. (1986) The Forms of Capital. In: Richardson, J., Ed., Handbook of Theory and Research for the Sociology of Education, Greenwood, New York, 241-258.

[12] Tulle, E. and Dorrer, N. (2012) Back from the Brink: Ageing, Exercise and Health in a Small Gym. Ageing and Society, 32, 1106-1127. https://doi.org/10.1017/S0144686X11000742

[13] Turner, B. (2000) The Possibility of Primitiveness: Towards a Sociology of Body Marks in Cool Societies. In: Featherstone, M., Ed., Body Modification, Sage, London, 39-50.

[14] Stewart, B., Smith, A. and Moroney, B. (2013) Capital Building through Gym Work. Leisure Studies, 32, 542-560. https://doi.org/10.1080/02614367.2012.697183

[15] Foucault, M. (1997) The Birth of Biopolitics. In: Rabinow, P., Ed., Ethics. Subjectivity and Truth. Essential Works of Foucault, 1954-1984, The New Press, New York, 73-79.

[16] Shilling, C. (2012) The Body and Social Theory. Sage, London, 140. https://doi.org/10.4135/9781473914810

[17] Bührmann, A. (2006) The Emerging of the Enterprising Self and Its Contemporary Hegemonic Status: Some Fundamental Observations for an Analysis of the (Trans-) Formational Process of Modern Forms of Subjectivation. Forum Qualitative Social Research, 6, Art. 16.

[18] Dilts, A. (2011) From 'Entrepreneur of the Self' to 'Care of the Self': Neo-Liberal Governmentality and Foucault's Ethics. Foucault Studies, 12, 130-146. https://doi.org/10.22439/fs.v0i12.3338

[19] Lupton, D. (2013) Understanding the Human Machine. IEEE Technology and Society Magazine, 32, 25-30. https://doi.org/10.1109/MTS.2013.2286431 
[20] Twigg, J. (2006) The Body in Health and Social Care. Palgrave MacMillan, New York, 8-13. https://doi.org/10.1007/978-1-137-02143-4

[21] Ritzer, G. (2011) The McDonaldization of Society. Sage, London, 14-17.

[22] Hochschild, A.R. (1983) The Managed Heart: Commercialization of Human Feeling. University of California Press, Berkeley.

[23] Brotheridge, C.M. and Grandey, A.A. (2002) Emotional Labor and Burnout: Comparing two Perspectives of "People Work". Journal of Vocational Behavior, 60, 17-39. https://doi.org/10.1006/jvbe.2001.1815

[24] Wharton, A.S. (1999) The Psychosocial Consequences of Emotional Labor. The Annals of the American Academy of Political and Social Science, 561, 158-176. https://doi.org/10.1177/000271629956100111

[25] Harvey, G., Vachhani, S.J. and Williams, K. (2013) Working Out: Aesthetic Labour, Affect and the Fitness Industry Personal Trainer. Leisure Studies, 21, 91-104.

[26] Smith Maguire, J. (2001) Fit and Flexible: The Fitness Industry, Personal Trainers and Emotional Service Labor. Sociology of Sport Journal, 18, 379-402. https://doi.org/10.1123/ssj.18.4.379

[27] Van Luevan, L.-C. (2002) When Frames Collide: Personalized Service Work and the Negotiation of Relational Boundaries. Ph.D. Dissertation, University of California, Los Angeles.

[28] George, M. (2008) Interactions in Expert Service Work: Demonstrating Professionalism in Personal Training. Journal of Contemporary Ethnography, 37, 108-131. https://doi.org/10.1177/0891241607309498

[29] Braun, V. and Clarke, V. (2006) Using Thematic Analysis in Psychology. Qualitative Research in Psychology, 3, 77-101. https://doi.org/10.1191/1478088706qp063oa

[30] McDowell, L. (2011) Working Bodies: Interactive Service Employment and Workplace Identities. John Wiley \& Sons, San Francisco, CA, 5. 


\section{Appendix: Interview Schedule}

1) Introduction

Where do you work at the moment?

Who are your clients? How do you recruit them?

How did you decide to become a fitness trainer?

When clients book personal training sessions with you, what happens next?

What is the procedure?

Where and how often do you train with a personal trainer at the moment?

How did you decide to hire a personal trainer in the first place?

Can you describe your trainer to me?

Can you describe a typical personal training session to me?

2) Main Body

How many clients do you currently have and can you tell me a bit about each

(Probes. What are their initial motivations, what is particular about this person? Do you know what they do for work, what hobbies they have, their private life etc.)

Do you have favourite clients as well? What makes them special?

When you work out with a client, how do you know that you have done a good job?

How would you describe your relationship to your clients?

What are typical conversation topics during training?

Can you produce a concrete memory of a client that you found difficult to work with?

Do you think about your clients when you are not at the gym, your working site?

Do you usually enjoy your training? (Probes. Which aspects do you like most? What don't you like?)

What are typical conversation topics during training?

Do you know anything personal about your trainer?

Do you think about your trainer and your training when you are not at the gym?

\section{3) Outro}

What do you like most about being a personal trainer?

Are there any aspects that you do not like about your job or find hard to accomplish?

Do you think you will stop having personal training at some point? Why/why not? 
Submit or recommend next manuscript to SCIRP and we will provide best service for you:

Accepting pre-submission inquiries through Email, Facebook, LinkedIn, Twitter, etc. A wide selection of journals (inclusive of 9 subjects, more than 200 journals)

Providing 24-hour high-quality service

User-friendly online submission system

Fair and swift peer-review system

Efficient typesetting and proofreading procedure

Display of the result of downloads and visits, as well as the number of cited articles Maximum dissemination of your research work

Submit your manuscript at: http://papersubmission.scirp.org/

Or contact jss@scirp.org 